\title{
Effect of Formation of Concentrated Stainless Steel Layer by Thermochemical Reaction and Addition of Hydrocarbon Gas on Sintered Part
}

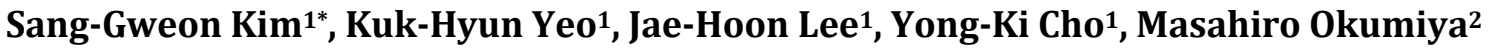 \\ ${ }^{1}$ Heat Treatment Technology R\&BD Group, Korea Institute of Industrial Technology, Siheung, Korea \\ ${ }^{2}$ Toyota Technological Institute, Nagoya, Japan \\ Email: ${ }^{\star}$ kimsg@kitech.re.kr
}

How to cite this paper: Kim, S.-G., Yeo, K.-H., Lee, J.-H., Cho, Y.-K. and Okumiya, M. (2018) Effect of Formation of Concentrated Stainless Steel Layer by Thermochemical Reaction and Addition of Hydrocarbon Gas on Sintered Part. Advances in Materials Physics and Chemistry, $\mathbf{8}$, 227-245.

https://doi.org/10.4236/ampc.2018.85015

Received: April 4, 2018

Accepted: May 27, 2018

Published: May 30, 2018

Copyright $\odot 2018$ by authors and Scientific Research Publishing Inc. This work is licensed under the Creative Commons Attribution International License (CC BY 4.0).

http://creativecommons.org/licenses/by/4.0/

\begin{abstract}
As the environmental load has recently increased, the use of sintered stainless steel for automobile parts is increasing to help weight reducing, high performance and external exposure. Although the low priced pre-mixed sintered stainless steel powder parts are used instead of the high priced pre-alloyed powder parts, there have been problems of poor corrosion resistance and high price because the parts are sintered at low temperature due to the change of final part size. This paper describes the alloying process of producing parts having high hardness and corrosion resistance through expanded high concentration chromium on the surface only of sintered steel, which is relatively easier to sinter, using the pack-chromizing technology to improve hardness and corrosion resistance to solve the problem. Notable is the coating where the activated-chromium formed during the pack-chromizing process remains in the coating layer can lower the friction coefficient of the coated layer to up to 0.1 . On the one hand, when the hydrocarbon gas was injected so as to promote the chromium-iron mixed carbide formed, the friction coefficient is increased to 0.4 with high hardness values. The thickness of the chromium alloying layer on the specimen can vary at the same temperature and same phase of the coating layer depending on which chromium resource materials (i.e. chromium or chromium-iron mixed powder) is used.
\end{abstract}

\section{Keywords}

Pack-Chromizing Technology, Sintered Stainless Steel, Sintered Steel, Tribological Test, Binding Chloride 


\section{Introduction}

Pack-chromizing technology is an excellent coating method used in combustion equipment for space, aircraft and power generation applications due to the excellent reproducibility and the outstanding material properties of anti-corrosion, anti-oxidization and usability in high temperatures [1] [2] [3].

The pack-chromizing process is widely used in surface coating technology to cost effectively improve the performance, the corrosion resistance, and the enhanced sulfuric environmental resistance of products. By means of chromizing ferrous alloys, a cemented (or alloyed) surface layer of $\mathrm{Cr}, \mathrm{Fe}$ and $\mathrm{C}$ is synthesized, and it enhances surface hardness, the wear resistance, and the corrosion resistance of treated materials [1] [2] [3].

In the case of CVD (Chemical Vapor Deposition), a precursor is required as the raw material for making new surface on the products [4]. However, in the case of pack-chromizing, no precursor is required; a simple mixture of the raw designed-approaching resource material and halide compound is converted into gas, inducing micro-alloying via diffuse-in reaction on the surface of products in the equipment lower than the evaporation temperature of the metal when it is heated in the atmosphere chamber. Therefore, the pack-chromizing process is more advantageous in controlling the composite coating and the material properties of coating depending on the composition of the raw material.

Although it is a very simple process, it is reliable and continuously applied in key part of power plant, large ship, aviation, and space, and thus the information on the process is tightly guarded.

Various chromizing processes such as the pack-cementation method, the molten salt technique, and the vacuum chromizing process have been developed [5]. It is a kind of process in-situ CVD (Chemical Vapor Deposition) with a three dimensional treatment with ease of method without using a high-priced precursor.

As the energy scale of power plants, offshore plants, semiconductor, and aviation and space has grown, the mechanical are also subject to more severe corrosion and environments of wear such as high temperature and pressure. Furthermore, since the size of the parts has increased and the shapes are complicated, it is required to make the protective coating procedure efficient with respect to cost and quality performance.

The designation about an advanced pack-chromizing technology, which is the diffusion coating technology through the pack cementation method to improve the raw material optimization and alloy process of the pack-chromizing, is considered as one of the recommendable treatments satisfied with high-wear resistivity, coating uniformity, and the simplicity of the process at the same time.

The advantage of this process is that, unlike the CVD process, it can control the surface alloy layer without using expensive precursor, discharges only hot gas, and exists in a solid form even after the reaction. The material discharged to outside with the ambient gas at the same time is the $\mathrm{Cl}_{2}$ gas that is generated by 
the reaction of the activator contained in the raw material contains almost no environmental hazard since it is dissolved to anion like the purified drinking water.

Figure 1(a) shows the surface corrosion after a sintered stainless steel part has been exposed to air for a year while Figure 1(b) shows the appearance of an aluminum sputtering coated product and Figure 1 (c) shows the corroded cross sectional surface but sound coated layer when a pack-chromizing treated sintered steel part was cut and exposed to air.

Since Presnov reported about the wear resistance of sintered steel by pack-chromizing technology to the variation carbon composition ratio in 1976, no other paper has reported especially developed reports about the sintered steels by pack-chromizing [6].

Kim et al. reported a phenomenon of a very low friction coefficient even though the product had a higher surface roughness after the sintered-steel coating made a dimple of hardened phase composed with high hardness as various precipitation chromium-carbide without deteriorating corrosion property.

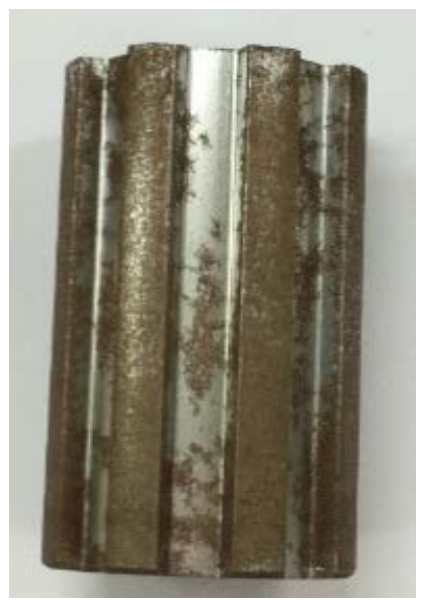

(a)

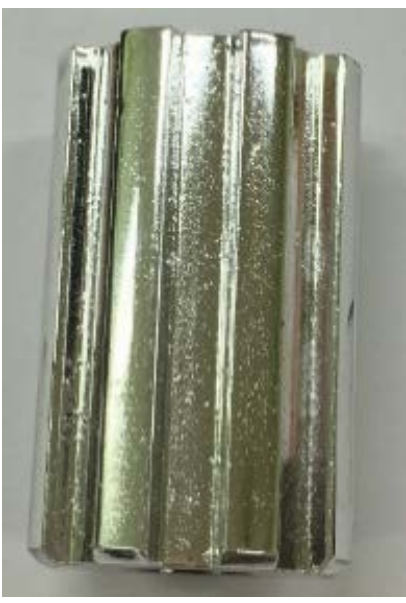

(b)

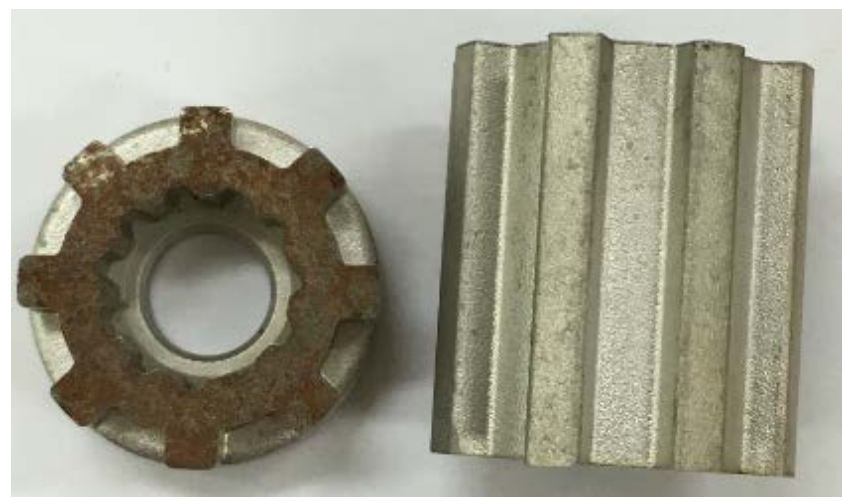

(c)

Figure 1. Comparison of sintered stainless steel parts and pack-chromizing treated sintered steel parts. (a) Sintered stainless steel, (b) Al sputtering sintered stainless steel, (c) pack-chromizing treated sintered steel. 
Furthermore, a unique advantage of pack-chromizing process is that superb anti-corrosion is established when the layers are densely formed. It also yields hardness and a very low friction coefficient due to the structure of coating layer acquired according to the process parameter and the contained elements. In the initial stage, while not many study results on pack-chromizing process were found, the research team had presumed that the friction coefficient of sintered steel was low because of the impact of carbide precipitated dimples with high hardness formed after the pack-chromizing process [7].

However, upon conducting additional research, it was found that it was difficult to explain the cause of low friction coefficient on account of high hardness and the formation of dimples alone.

It was determined that the existence or formation of a certain amount of ammonium chloride crystals used in a small quantity as the activator affected the friction coefficient.

It was also observed that depending on the composition of materials in the pack, the formation behavior over the coating varied and affected the hardness and thickness of the formed coating layer. Further, it was found that, according to the composition, the process parameters affected the amount of chloride contained in the coating layer which in turn affects the friction coefficient.

In this study, the coating process was based on the formation of chromium chloride (metal halide gas) with hydrocarbon (acetylene) gas in situ during the processing. A metallic chromium and chromium-ferrous-alloys resource mixed with halide activator $\left(\mathrm{NH}_{4} \mathrm{Cl}\right)$ were used as reagents and the surface alloying process was obtained by means of heating a batch in dynamic purging and then holding an argon static atmosphere and adding hydrocarbon gas.

\section{Experimental Details}

\subsection{General Pack-Chromizing Process}

The equipment structure for pack-chromizing process is shown in Figure 2. The sintered steels were treated in a mixture powder of $99.5 \%$ purity $\mathrm{Cr}$ (10 wt\%), $\mathrm{NH}_{4} \mathrm{Cl}(0.4 \mathrm{wt} \%)$, and $\alpha-\mathrm{Al}_{2} \mathrm{O}_{3}(89.6 \mathrm{wt} \%)$ as master alloy, activator, and inert filler, respectively. The KCC process heated the material from room temperature $\left(\sim 25^{\circ} \mathrm{C}\right)$ up to $850^{\circ} \mathrm{C}-1000^{\circ} \mathrm{C}$ in 1 to 2 hours soaking and then maintained it at process temperature $\left(850^{\circ} \mathrm{C}-1000^{\circ} \mathrm{C}\right)$ for 25 hours. The pressure of the chamber was initially vacuumed until $10^{-1}$ Torr $(13.33 \mathrm{~Pa})$ to remove oxygen and to prevent any side effects, and to sustain the same atmospheric pressure and conditions with the argon gas flowing at 1.0 liter/min during the reaction process.

The specific chemical compositions of sintered steel were measured by a spectrometer (AMETEK, Spectrolab), and the results are shown in Table 1.

\subsection{Mixture Gas Ambient with Hydrocarbon Gas}

Figure 3 shows the heating cycles of pack-chromizing process and patterns with hydrocarbon gas under the same atmospheric pressure and condition with 


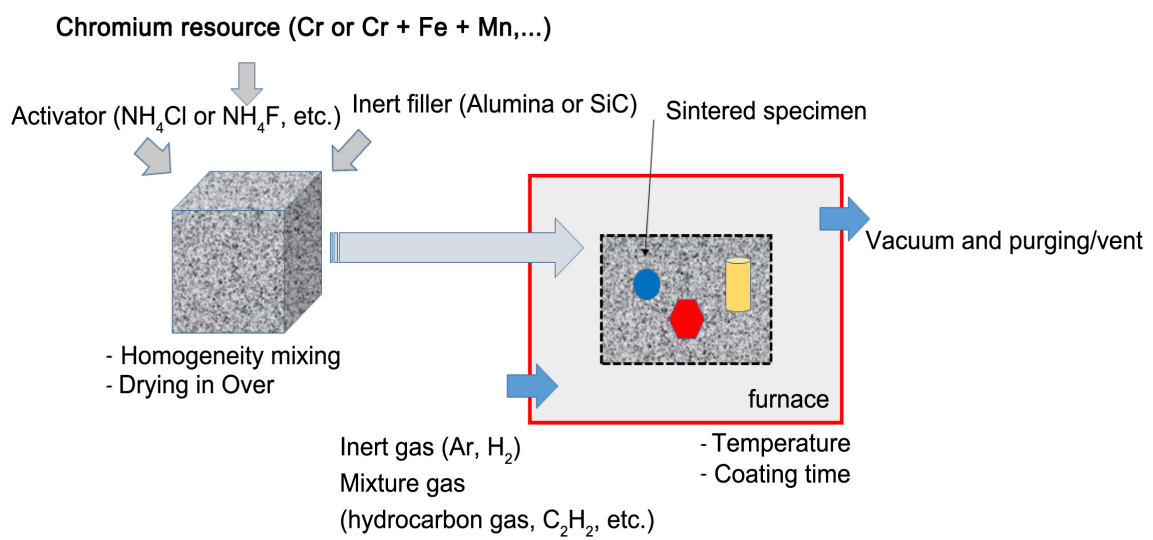

Figure 2. Concept of pack-chromizing process including hydrocarbon atmosphere.

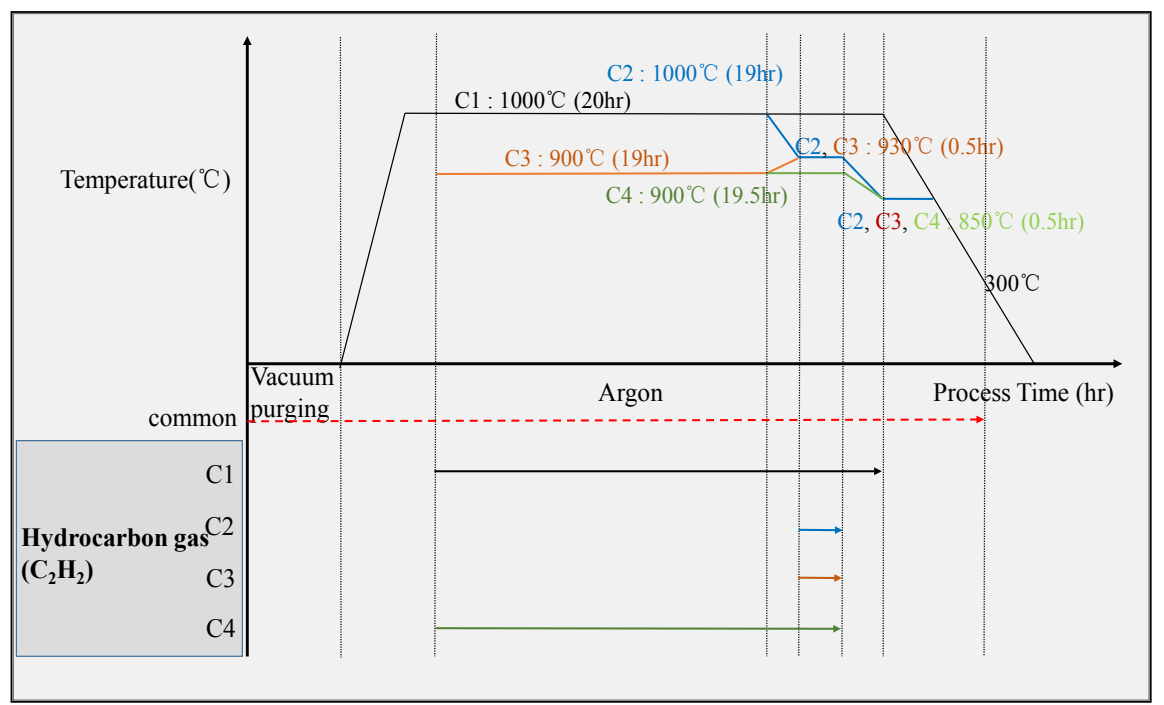

Figure 3. Heating cycles of the pack-chromizing process and patterns with hydrocarbon gas.

Table 1. Chemical composition of the sintered steel.

\begin{tabular}{cccccccccccc}
\hline AISI4140 & $\mathrm{C}$ & $\mathrm{O}$ & $\mathrm{N}$ & $\mathrm{P}$ & $\mathrm{S}$ & $\mathrm{Si}$ & $\mathrm{Mn}$ & $\mathrm{Cr}$ & $\mathrm{Cu}$ & $\mathrm{Ni}$ & $\mathrm{Fe}$ \\
\hline $\begin{array}{c}\text { Concentration } \\
(\text { wt\% })\end{array}$ & 0.6 & 0.14 & 0.002 & 0.009 & 0.018 & $<0.01$ & 0.2 & 0.07 & 0.10 & 0.08 & $\mathrm{Bal}$. \\
\hline
\end{tabular}

flowing argon gas of 1.0 liter/min and additive hydrocarbon gas $\left(\mathrm{C}_{2} \mathrm{H}_{2}\right)$ during the reaction process. The step of the carbide formation processes is typically performed at different temperatures from $850^{\circ} \mathrm{C}$ to $1000^{\circ} \mathrm{C}$ for durations of about 20 hours, limited by the diffusion and reaction kinetics involved.

\subsection{Effect of Chromium only and Chromium-Iron Mixture Resource}

The pack-chromizing resource is composed of chromium of $99.5 \%$ purity as the coating base metal taking up $20 \mathrm{wt} \%$ of the entire composition, the 70:30 mix- 
ture of chromium of $99.5 \%$ purity (60 mesh) and iron powder of $99.5 \%$ purity (60 mesh) taking up $20 \mathrm{wt} \%$, ammonium chloride, the activator taking up 0.5 $\mathrm{wt} \%$ and the remaining of powder made of $\alpha-\mathrm{Al}_{2} \mathrm{O}_{3}(79.5 \mathrm{wt} \%)$. The preparation is performed by putting the sample in the powder.

To remove moisture inside, the sample container including the pack is placed and maintained in the oven preheated to $100^{\circ} \mathrm{C}$. After the removal of moisture, the container is placed in the atmosphere chamber as shown in Figure 1, pressurized with argon gas and maintained for 30 minutes for purging. After purging followed by the minimization of argon gas to 1.0 liter/min, the temperature is increased.

The pack-chromizing process is maintained for about 1 hour after the chamber temperature increases from the room temperature to $930^{\circ} \mathrm{C}, 970^{\circ} \mathrm{C}$ and $1020^{\circ} \mathrm{C}$. Then, after maintaining the process for 5 hours, the chamber is turned off. After having it cooled down to room temperature, the sample is removed from the chamber and the thickness of the micro-alloying with diffusion element is formed.

\section{Results and Discussion}

Sintered steels generally show a filling surface in proportion to the increasing temperature (see Figure 4 and Figure 5) after pack-chromizing. As the pack-chromizing process condition was below sintering temperature, the

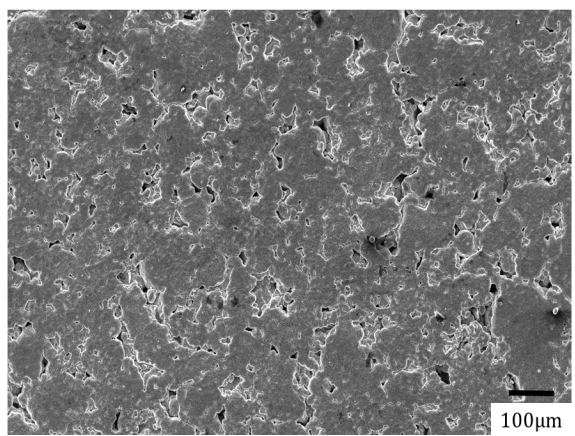

(a)

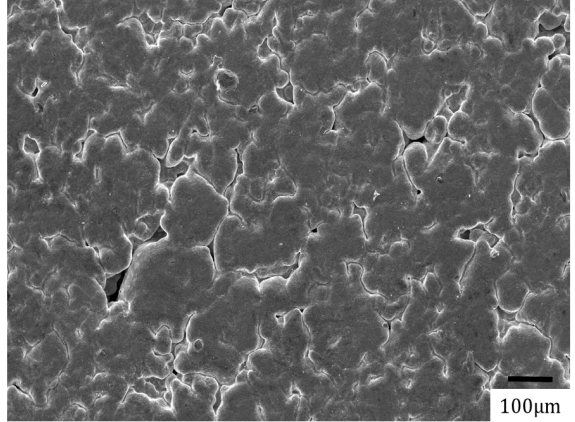

(b)

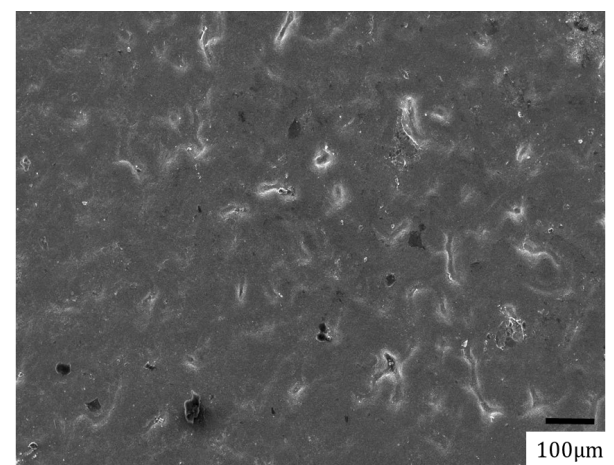

(c)

Figure 4. SEM images of the surface of coated sintered steel after pack-chromizing process as a function of temperature. (a) $850^{\circ} \mathrm{C}$. (b) $900^{\circ} \mathrm{C}$. (c) $1000^{\circ} \mathrm{C}$. 


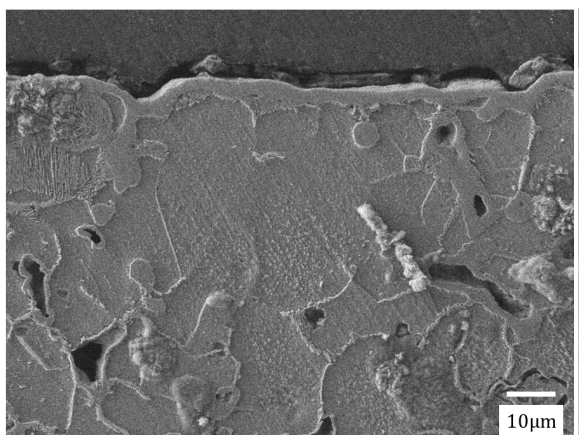

(a)

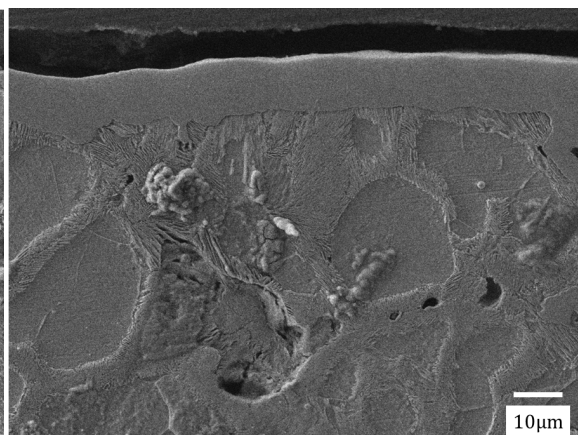

(b)

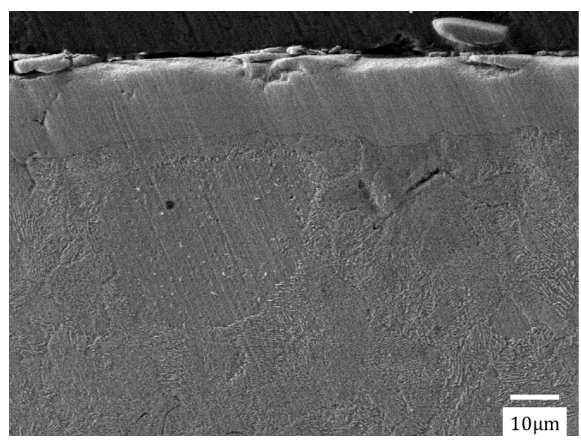

(c)

Figure 5. SEM images of cross-section of pack-chromizing treated sintered steel as a function of temperature. (a) $850^{\circ} \mathrm{C}$. (b) $900^{\circ} \mathrm{C}$. (c) $1000^{\circ} \mathrm{C}$.

chromium that diffused and reacted on the surface took part in filling voids, thus reducing surface porosity (see Figures $4(\mathrm{a})$-(c)).

Figures 5(a)-(c) show a cross-section of pack-chromizing sintered steel with high chromium concentration diffused on the surface that generally helps to form ferrite structure induced by pack-chromizing with a slow cooling rate.

After pack-chromizing process, the sintered steels had lower friction coefficients than those of the untreated specimens. As shown in Figure 6, the friction coefficient of a pack-chromizing treated specimen was lower by up to $1 / 3-1 / 6$ times the untreated specimen in the condition of the load weight of $5 \mathrm{~N}$ and the wear velocity of $10 \mathrm{~mm} / \mathrm{sec}$. All of the friction coefficients of the coated specimens kept appreciably dropped values around 0.2 below.

Sen et al. reported that the friction coefficient values from 0.38 to 0.55 by $\mathrm{Cr}_{3} \mathrm{C}_{2}$ and $\mathrm{Cr}_{7} \mathrm{C}_{3}$ carbides although the substrate was not sintered steel [8]. However, it is still not enough to explain the phenomenon of the lower friction coefficient of the sintered steels after pack-chromizing process.

Kim et al. had carefully insisted on a low friction at near 0.1 , a reason of dimple with high hardness carbide formation [7].

The metal carbide $\left(\mathrm{M}_{7} \mathrm{C}_{3}, \mathrm{M}=\mathrm{Cr}, \mathrm{Fe}\right)$ and $\mathrm{Cr}_{3} \mathrm{C}_{2}$ carbides were observed on the surface of the sintered steel after the pack-chromizing treatment by analyzing XRD pattern as shown in Figure 7 [6] [7] [8]. These carbides make the layer's hardness increase up to around $1700-2000 \mathrm{HV}_{0.05}$. The hardened layer with the carbide contributed to the sintered steel having wear resistance and a 


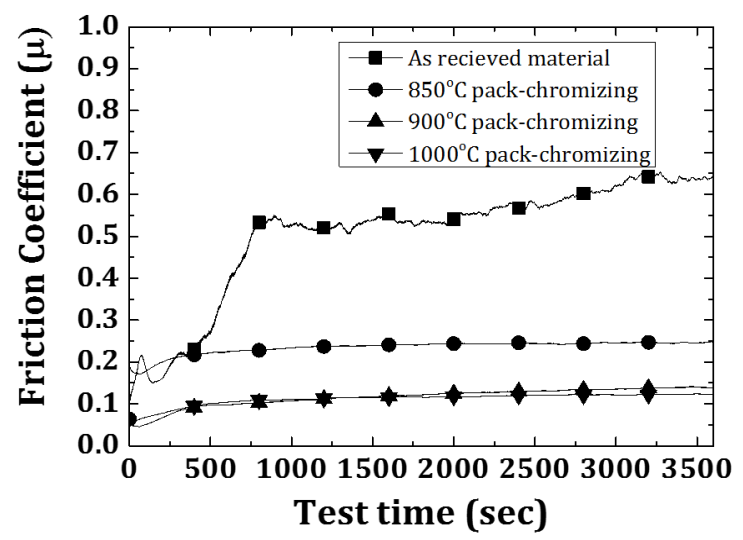

Figure 6. Results of tribological test as function of pack-chromizing temperatures.

low friction coefficient [6] [7].

Further investigation was conducted in the attempts to try to explain the reasons for the low friction coefficient of the chromium coating on sintered-steel by EDAX and XPS analysis. As the results, after pack-chromizing treatment, the morphology of the treated sintered-surface was a modified dense wrinkled (or dimpled) structure although the sintered-steels originally had a porosity surface.

Thus it is concluded that the low friction coefficient property stems from not only the intrinsic porosity but also the dimple morphology made up of the hardened carbides.

Figures 8(a)-(c) show a binding energy of $\mathrm{Cr}, \mathrm{Fe}, \mathrm{O}, \mathrm{C}, \mathrm{Cl}$ each elements of coating layer by XPS analyzer as function of pack-chromizing coating temperature (a) $850^{\circ} \mathrm{C}$, (b) $900^{\circ} \mathrm{C}$, and (c) $1000^{\circ} \mathrm{C}$. And especially, it showed a Cr-peak $\left(2 \mathrm{P}_{3 / 2}\right)$ and Cr-peak $\left(2 \mathrm{P}_{1 / 2}\right)$ of metal-chloride with $\mathrm{M}_{23} \mathrm{C}_{6}(\mathrm{M}=\mathrm{Cr}, \mathrm{Fe})$ carbide, $\mathrm{Cr}_{2} \mathrm{O}_{3}$, and included a chromium-chloride onto the chromium alloying layer not to be shown in the XRD analysis.

Therefore, the pack-chromizing treated sintered-steel has been affected by a low friction coefficient phenomenon by a sliding wear testing method. It will tell you why to assert importance for the concentration of metal-chloride not to be attracted with its counter-parts during tribological tests with carbides including a high chromium alloying layer that includes both EDAX and XPS with a low friction coefficient.

Figure 9(a) for $\mathrm{C} 1$ and Figure 9(b) for $\mathrm{C} 2$ show similar morphologies on that point of the same temperature as Figure $3(\mathrm{c})$ at $1000^{\circ} \mathrm{C}$. Figure 9 (c) for $\mathrm{C} 3$ and Figure $9(\mathrm{~d})$ for $\mathrm{C} 4$ have shown similar images of the specimens surface comparing with Figure 3(a) and Figure 3(b) according to the coating temperature 850, and $900^{\circ} \mathrm{C}$, respectively.

Chromium-rich sintered steel generally showed ferrite phase (see Figures 4(a)-(c)). However, it was determinately shown that it had a carbide-rich phase (see Figure 10(a) and Figure 10(b)) when the cross-section of the specimens after the pack-chromizing including hydrocarbon gas was visually inspected by an optical microscope. 


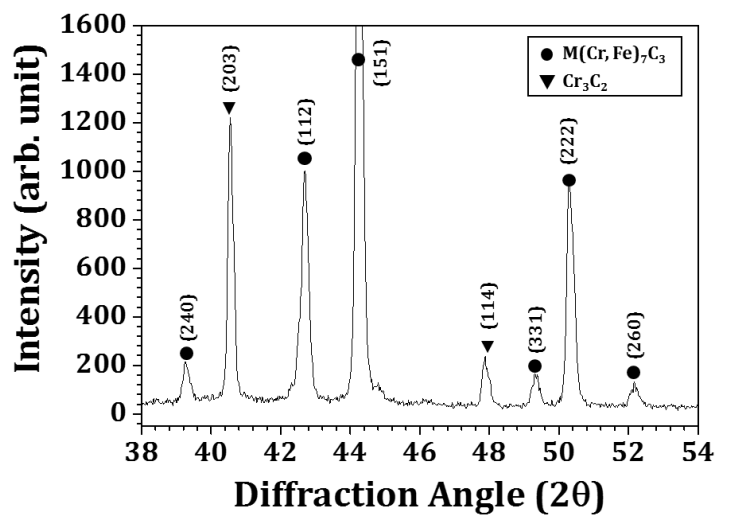

(a)

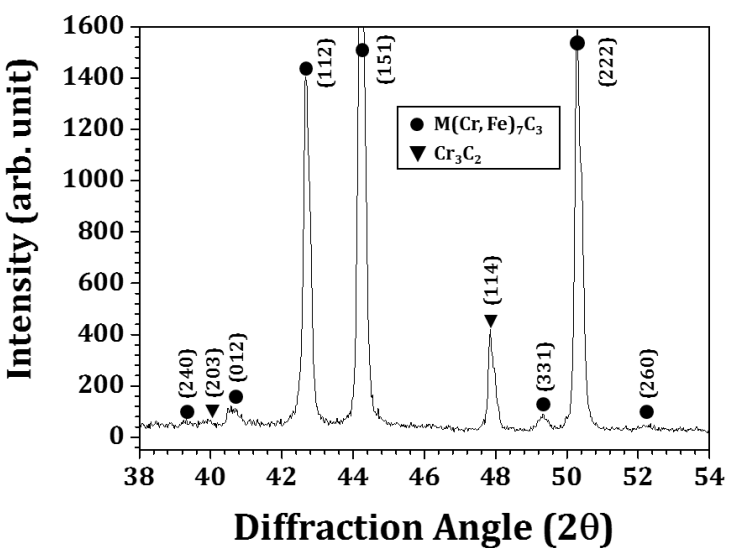

(b)

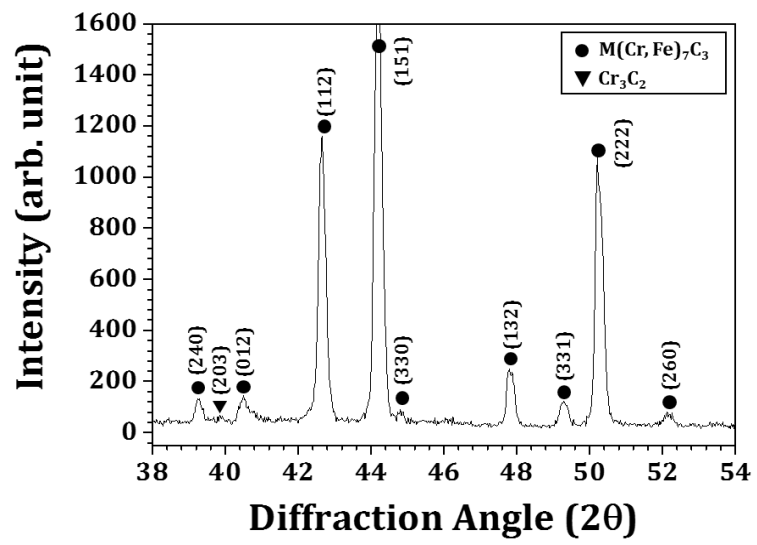

(c)

Figure 7. The results of the X-ray diffraction pattern analysis as a function of temperature. (a) $850^{\circ} \mathrm{C}$. (b) $900^{\circ} \mathrm{C}$. (c) $1000^{\circ} \mathrm{C}$.

The carbide forming pack-chromizing process resulted in different surface hardness and hardness profiles as shown in Figure 11.

The hardness values, around $1200-1800 \mathrm{HV}_{0.025}$, is a result of chromium-rich coating with the precipitated-carbide phase $\mathrm{M}_{7} \mathrm{C}_{3}$. This yields a very high hardness of the surface. The pack-chromizing processes in the case of $\mathrm{C} 1, \mathrm{C} 2$, and $\mathrm{C} 3$ (see Figure 2) resulted in formation of $\mathrm{M}_{7} \mathrm{C}_{3}$ carbide above $930^{\circ} \mathrm{C}$. However, the 

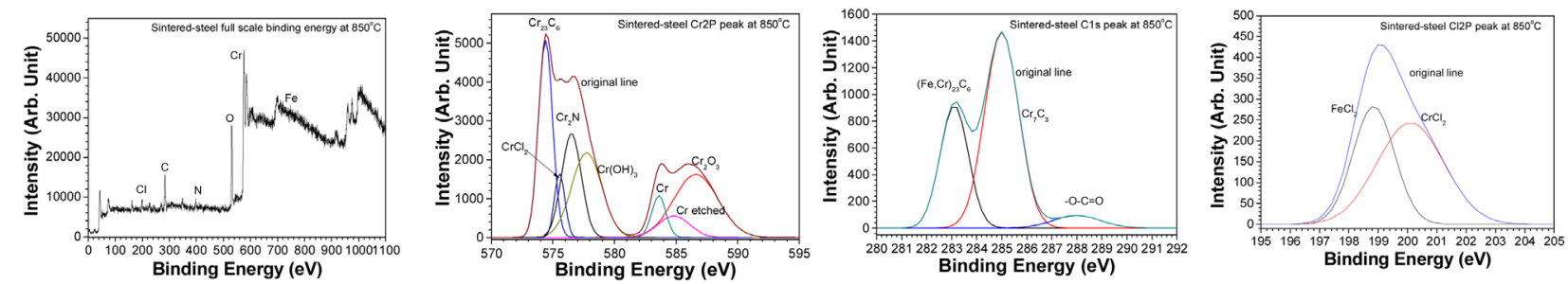

(a)
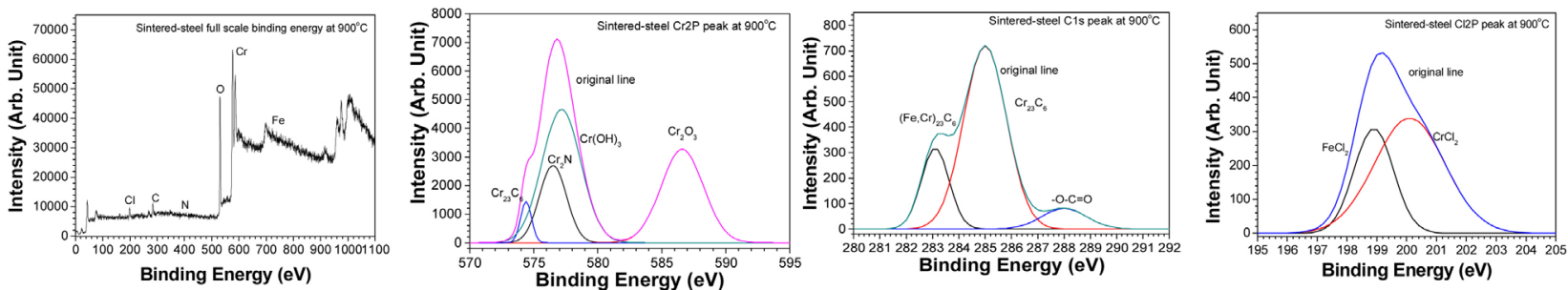

(b)
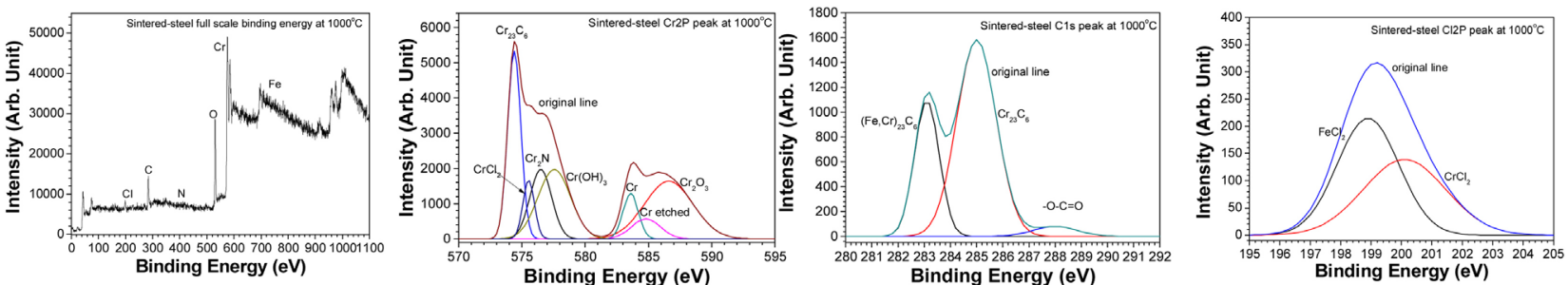

(c)

Figure 8. XPS analysis results of pack-chromized surface layer on sintered-steels as a function of temperature. (a) $850^{\circ} \mathrm{C}$. (b) $900^{\circ} \mathrm{C}$. (c) $1000^{\circ} \mathrm{C}$.

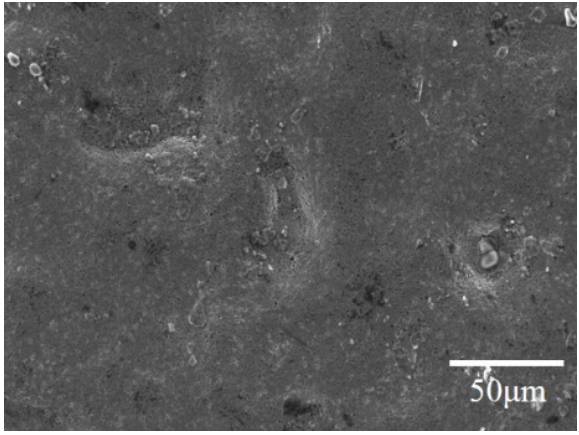

(a)

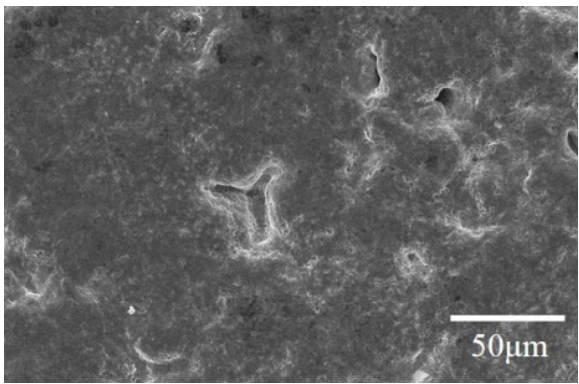

(c)

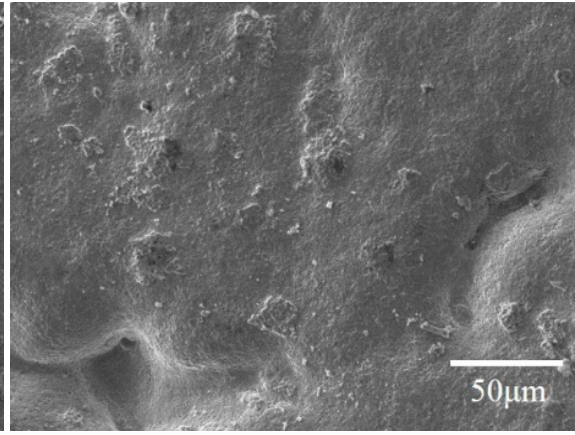

(b)

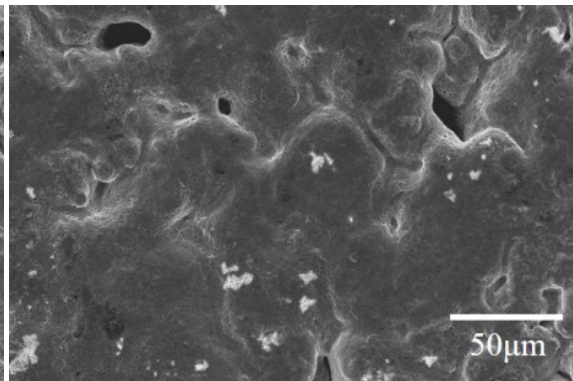

(d)

Figure 9. SEM images of the surface of pack-chromized surface layer created in hydrocarbon atmosphere for each condition (C1-C4). (a) C1. (b) C2. (c) C3. (d) C4. 


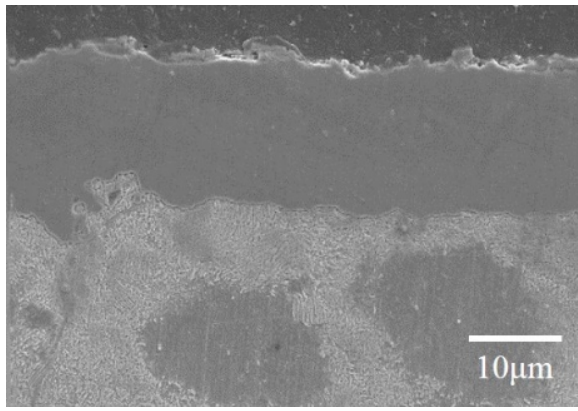

(a)

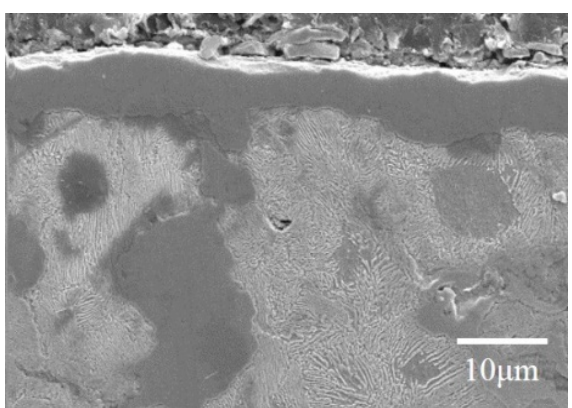

(c)

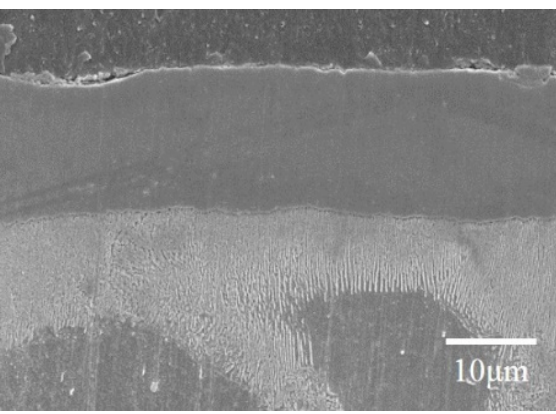

(b)

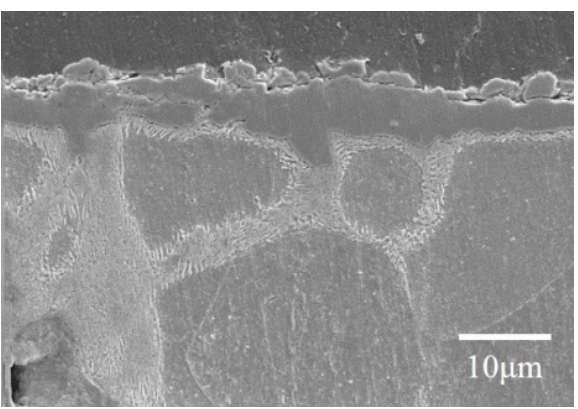

(d)

Figure 10. SEM images of cross-section of pack-chromizing layer for each condition (C1-C4). (a) C1. (b) C2. (c) C3. (d) C4.

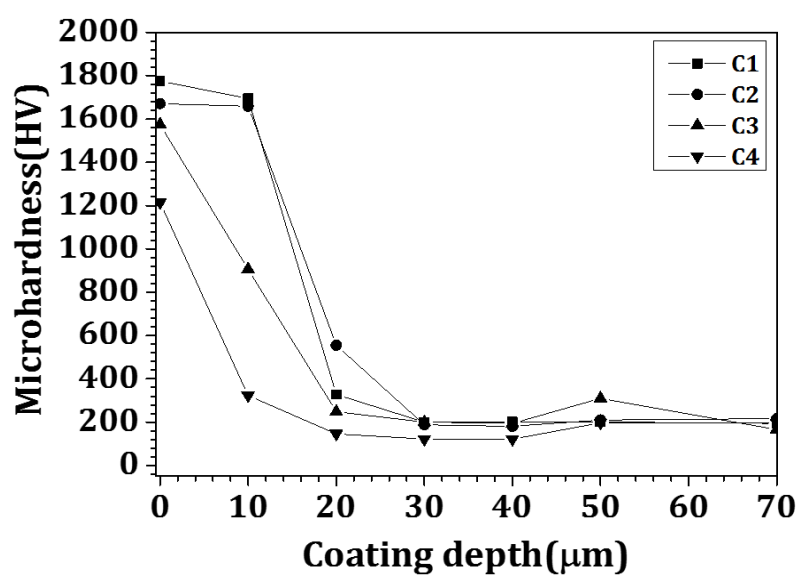

Figure 11. Micro-Vickers hardness profile of pack-chromizing treated layer for each condition.

C4 process showed a lower hardness value comparing to other tested processes because it did not reach the limiting temperature, well-known activation energy level, of metal carbide formation.

The chromium-iron carbides complex, $\mathrm{M}_{7} \mathrm{C}_{3}(\mathrm{M}=\mathrm{Cr}, \mathrm{Fe})$ and $\mathrm{Cr}_{3} \mathrm{C}_{2}$ were observed on the surface of the sintered steel after pack-chromizing process by analyzing XRD as shown in Figures 12(b)-(d). The hardened layer with the carbides resulted in the sintered steel to have wear resistance and a low friction coefficient.

However, the results of XRD diffraction patterns of pack-chromizing 


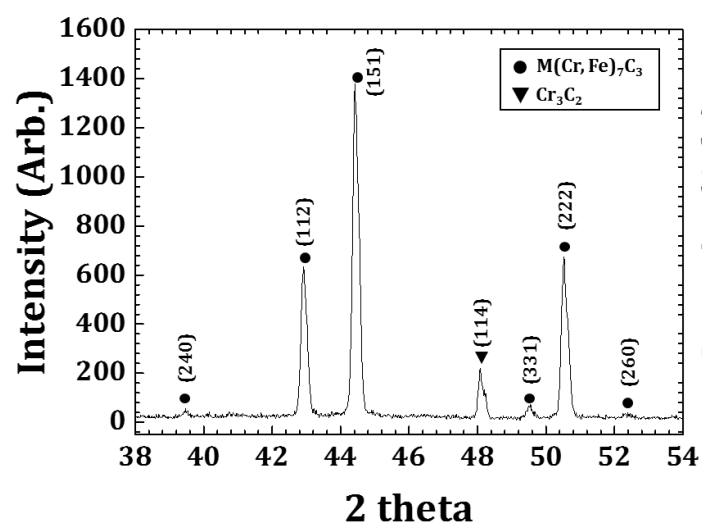

(a)

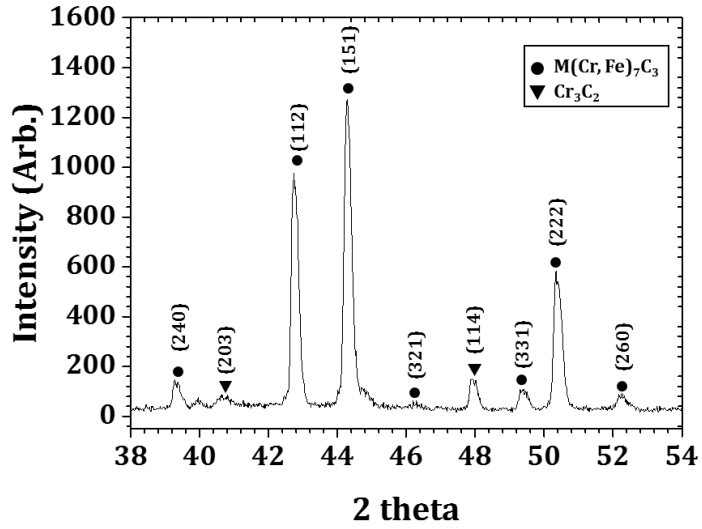

(c)

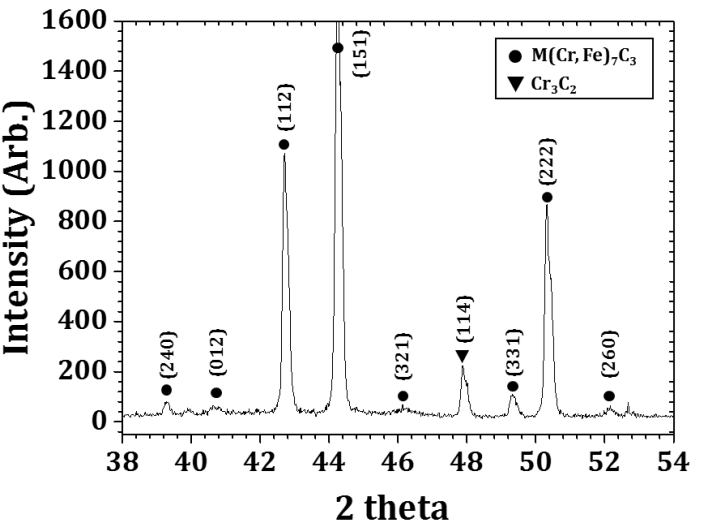

(b)

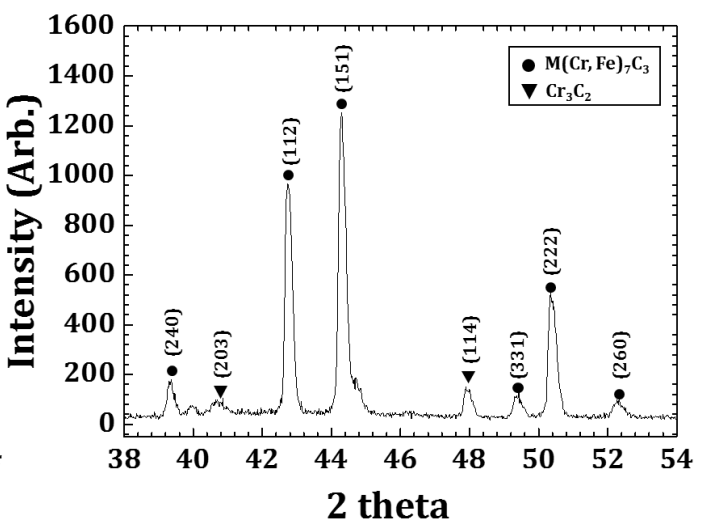

(d)

Figure 12. The results of the X-ray diffraction analysis of the sintered steel processed using pack-chromizing process with a hydrocarbon gas atmosphere. (a) C1. (b) C2. (c) C3. (d) C4.

processes with hydrocarbon gas atmosphere clearly show different carbide peak intensity with similar temperature conditions (refer to Figures 12(b)-(d)). Enriched carbon source from cracked hydrocarbon gas and chromium-iron carbide $\mathrm{M}_{7} \mathrm{C}_{3}$ with higher carbon ratio, took part in reactions from Equations (5) and (6). The results of XRD diffraction pattern in Figure 12(a) and Figure 12(b) showed similar tendency to the hardness values of chromium coating layers with increased dominant carbides.

In the previous research, Sen et al. reported that the friction coefficient increased from 0.41 to around 0.5 by pack-chromizing, although the substrate was not the sintered steel [8]. However, it is still not enough to explain the phenomenon of the lower friction coefficient of the sintered steels after pack-chromizing treatment.

Our previous study carefully insisted on a low friction at near 0.1 , a reason of dimple with high hardness carbide formed [7]. The trend of friction coefficient on the pack-chromizing treated layer of sintered steel surface processed in hydrocarbon gas conditions have been clearly shown at around below 0.5 in Figure 13.

After pack-chromizing treatment, the sintered steel sample has lower friction 


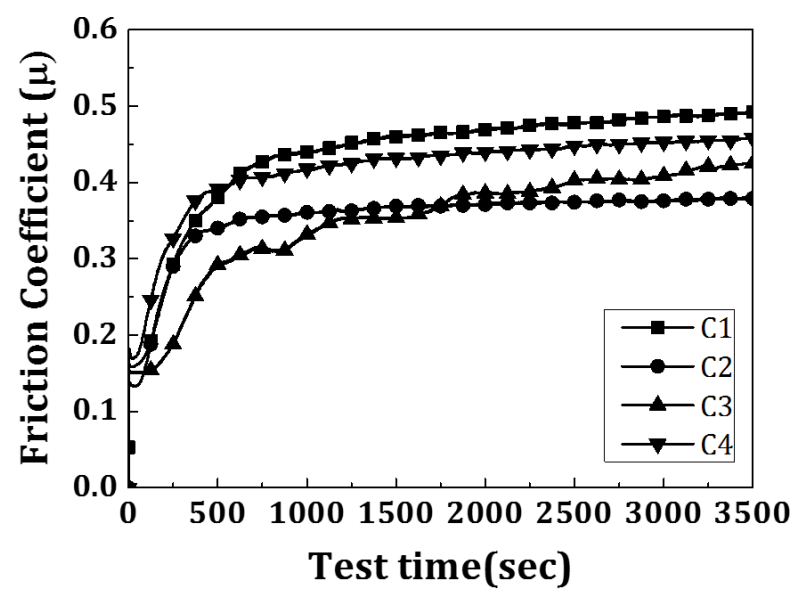

Figure 13. Results of tribological test for pack-chromizing process with hydrocarbon gas atmosphere for each conditions.

coefficients compared to the non-treated specimens.

As shown in Figure 14, in the conditions of load weight of $5 \mathrm{~N}$ and wear velocity of $10 \mathrm{~mm} / \mathrm{sec}$. The carbide formation is advantageous or the reaction is performed by not only using chromium material, but mixing Fe uniformly for the layer, as in the case of Figure 14, the friction coefficient is observed to be low by approx. 0.2 . In the case of Figure 14, 7Cr-3Fe shows friction coefficient in the range of $0.2-0.5$ which is higher than that of the previous case.

In this study, regarding the fact that the greatest friction coefficient acquired is positioned near to $0.2-0.4$, Sen et al. argue that the friction coefficient is lowered by the formation status of carbide [8]. However this hypothesis is not enough to explain the drop to 0.2 for the sintered specimen, as carbide formation would have resulted only in a friction coefficient of 0.5 , and by means a value lower than 0.5 .

Therefore, the created materials during the pack-chromizing process are reviewed again in this study to explain the cause of low friction coefficient for the sintered specimen despite similar conditions in the pack-chromizing process.

The chemical reaction between the main material of $\mathrm{Cr}$ and the activator of $\mathrm{NH}_{4} \mathrm{Cl}$ (Ammonium Chloride) can be summarized as follows:

The reaction in the pack-chromizing resource mixture (showed only an equilibrium gas mixture for active reaction):

$$
\begin{gathered}
\mathrm{NH}_{4} \mathrm{Cl}(\mathrm{s}) \rightarrow \mathrm{NH}_{4} \mathrm{Cl}(\mathrm{g})=\mathrm{NH}_{3}(\mathrm{~g})+\mathrm{HCl}(\mathrm{g}) \\
2 \mathrm{NH}_{3}(\mathrm{~g}) \rightarrow \mathrm{N}_{2}(\mathrm{~g})+3 \mathrm{H}_{2}(\mathrm{~g}) \\
2 \mathrm{HCl}(\mathrm{g})+\mathrm{Cr}(\mathrm{s})=\mathrm{CrCl}_{2}(\mathrm{~g})+\mathrm{H}_{2}(\mathrm{~g}) \\
\mathrm{CrCl}_{x}(\mathrm{~g})+1 / 2 x \mathrm{H}_{2}(\mathrm{~g})=\mathrm{Cr}(\mathrm{s})+x \mathrm{HCl}(\mathrm{g})
\end{gathered}
$$

The gaseous hydrochloric acid is subsequently transferred to surface of chromium resource, where it reacts again and is converted into $\mathrm{CrCl}_{X}$ (reaction 3). And an added hydrocarbon gas reaction: 


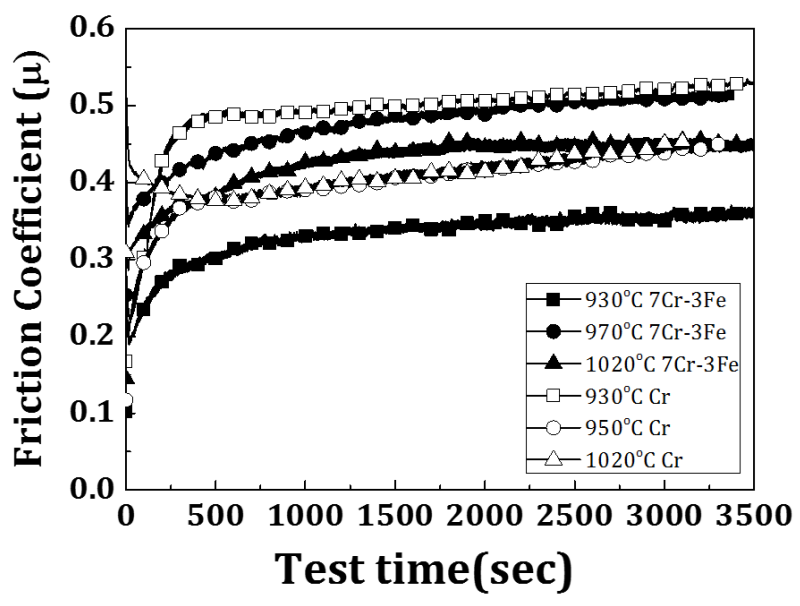

Figure 14. The friction coefficient change of pack-chromizing treated layer following the temperature change.

$$
\begin{gathered}
\mathrm{C}_{2} \mathrm{H}_{2}(\mathrm{~g})+2 \mathrm{Cl}(\mathrm{g}) \rightarrow 2 \mathrm{HCl}(\mathrm{g})+2 \mathrm{C}(\mathrm{g}) \\
2 \mathrm{C}(\mathrm{g})+\mathrm{Cr}, \mathrm{Fe}(\mathrm{s}) \rightarrow(\mathrm{Cr}, \mathrm{Fe})_{x} \mathrm{C}_{y}(\mathrm{~s})
\end{gathered}
$$

The gas of $\mathrm{HCl}(\mathrm{g})$ in Equation (5) makes a contribution to reaction gas support to the Equation (3) and it can take part in making the metal halide gas.

The reaction in the coating layer or surface:

$$
\begin{gathered}
\mathrm{CrCl}_{2}(\mathrm{~g})+\mathrm{H}_{2}(\mathrm{~g})=\mathrm{Cr}(\mathrm{s})+2 \mathrm{HCl}(\mathrm{g}) \\
2 \mathrm{HCl}(\mathrm{g})+\mathrm{Cr}, \mathrm{Fe}(\mathrm{s})=(\mathrm{Cr}, \mathrm{Fe})_{x}(\mathrm{~g})+\mathrm{H}_{2}(\mathrm{~g})
\end{gathered}
$$

The reactions (1) - (4) are between the basic chromium and the activator and they proceed to the stage when the main reaction material of the chromium alloying layer is created. In this stage, it is predicted that, if reaction (4) does not occur well or $\mathrm{HCl}$ causes any reaction with other materials, reaction (3) forming the gas resource from alloy material by the activator will be reduced causing a thin alloying layer.

Otherwise, the model of mixed activator depleted zone describes over $900^{\circ} \mathrm{C}$ in Figure 15 that, since the main substances of the deposition layer as well as the base material are iron $(\mathrm{Fe})$ and chromium $(\mathrm{Cr})$, due to the local depletion phenomenon of the activator, the pressure formed in the micro-alloying layer is not much lower than the pressure moving in the pack-chromizing resource by the chemical reaction so that the materials in the deposition layer ( $\mathrm{Cr}$ or $\mathrm{Cr}$-Fe alloy) return to the pack-chromizing resource as well by the reversed reaction (like catalyst).

The total added amount of 7Cr-3Fe mixture of chromium and iron in the reactive alloying's base material for the maximum suppression of the reversed reaction by the activator, and the section of coating layer by the reaction with the activator in the same condition are shown in the following Figure 16(a) and Figure $16(\mathrm{~b})$. When processed at $1020^{\circ} \mathrm{C}$, the micro-alloying layer is found to be approx $30 \%$ thicker in case of high purity chromium micro-alloying layer (12 


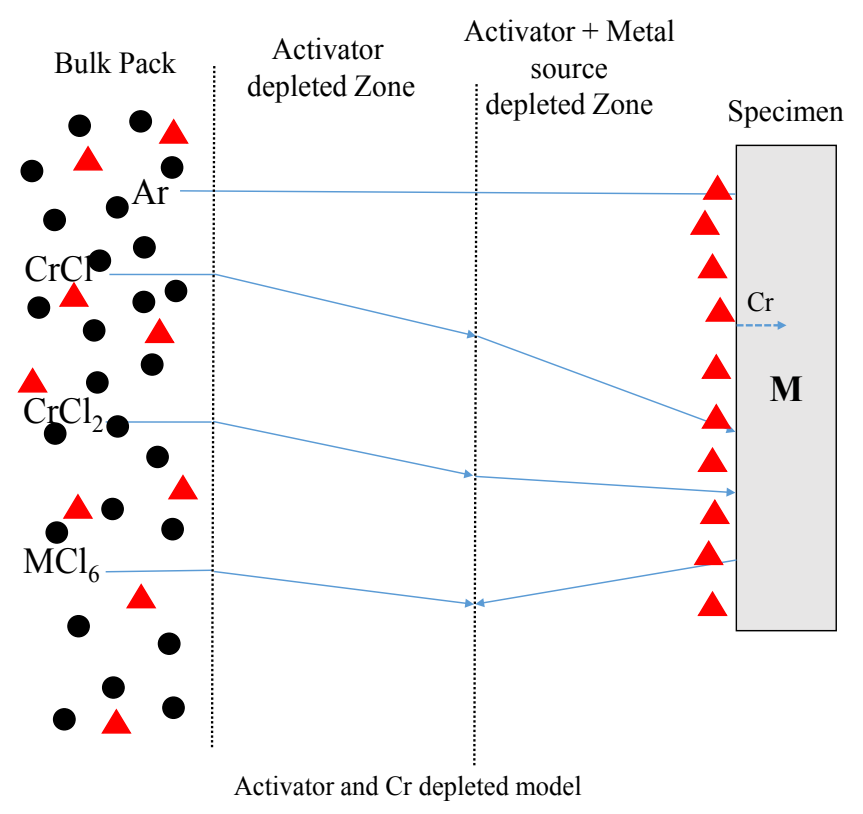

Figure 15. Activator depleted zone model.

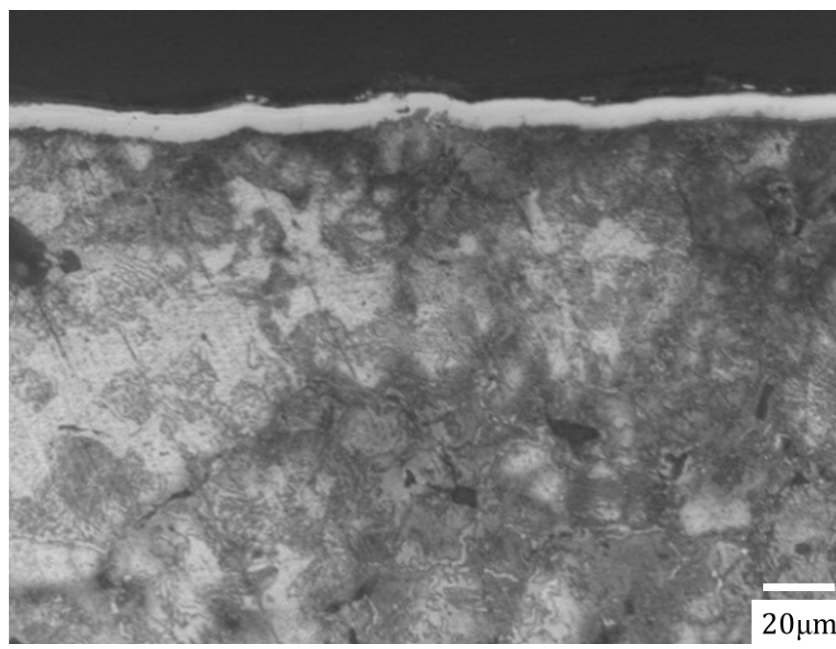

(a)

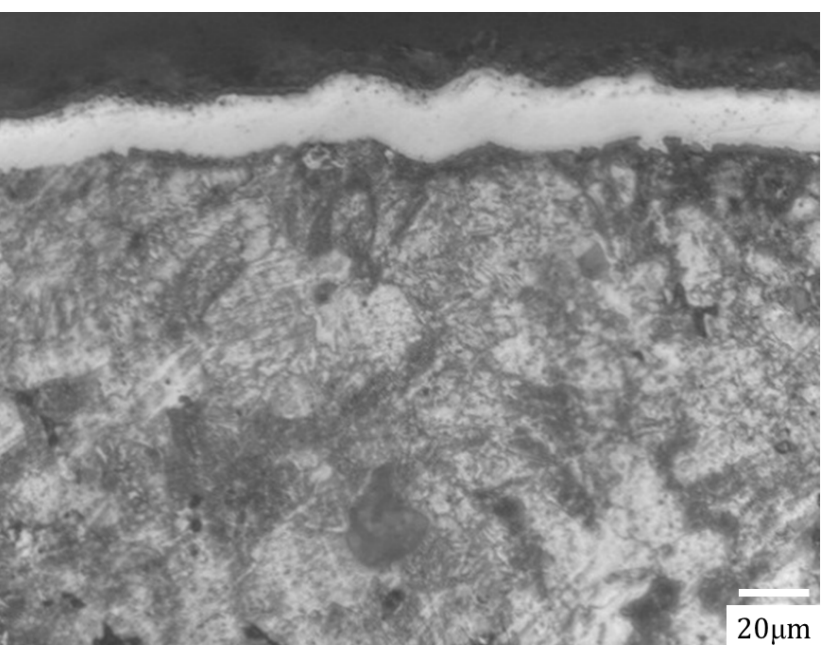

(b)

Figure 16. Observation results of coating sections according to the mixtures of high purity chromium and $7 \mathrm{Cr}-3 \mathrm{Fe}$ mixture resource in the material. (a) Cr. (b) 7Cr-3Fe.

$\mu \mathrm{m})$ than in the case of $7 \mathrm{Cr}-3 \mathrm{Fe}$ mixture resource treatment $(16 \mu \mathrm{m})$. At this time, the coating surface is as shown in Figure 17. It may be noted that there are fewer pores on the surface in the case of $7 \mathrm{Cr}-3 \mathrm{Fe}$ mixture resource treatment compared to the case of high purity chromium treatment.

Also, the composition of the coating material by EDS under the same condition is analyzed as shown in Figure 18. Also, the changes of major elements are compared by temperature and time as shown in Figure 18.

When comparing the composition of substance observed in EDS and XPS, in EDS, absolutely no $\mathrm{Cl}$ is found after the process at $930^{\circ} \mathrm{C}$ for 20 hours while more than $3 \%$ of $\mathrm{Cl}$ is found in the form of $\mathrm{CrCl}_{x}$ even in the surface etching 

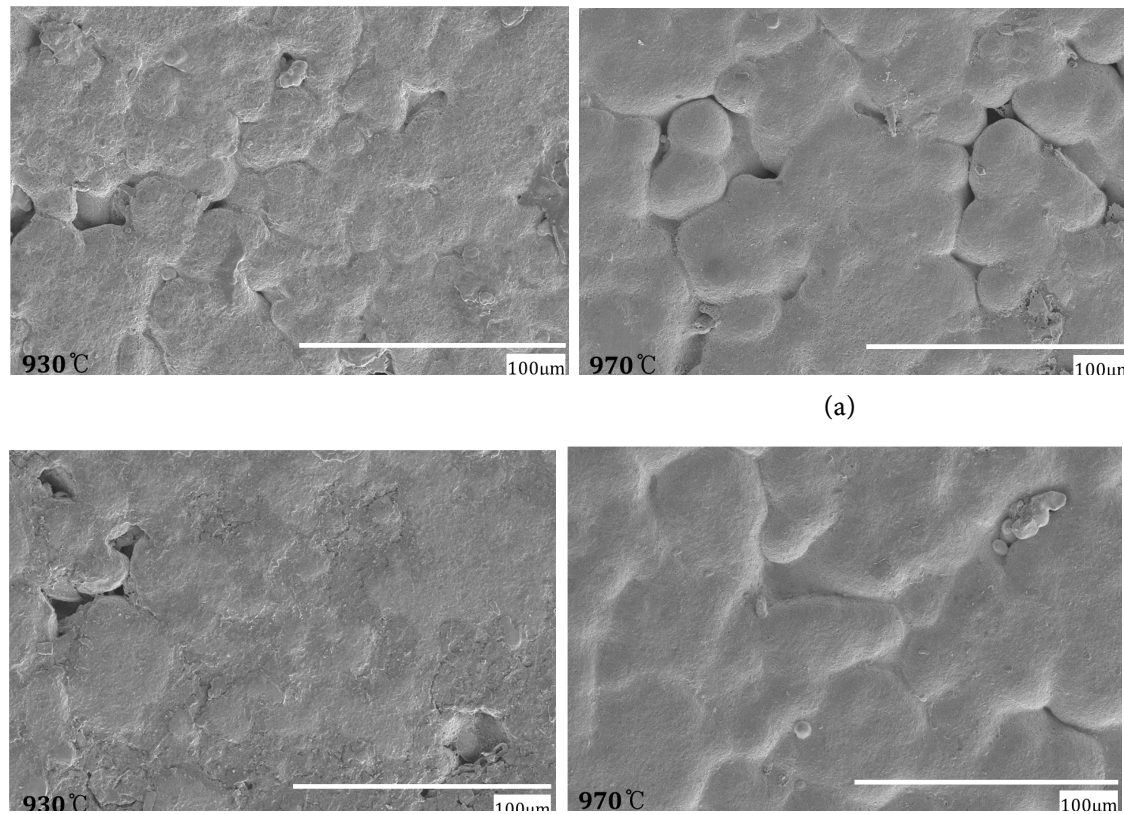

(b)

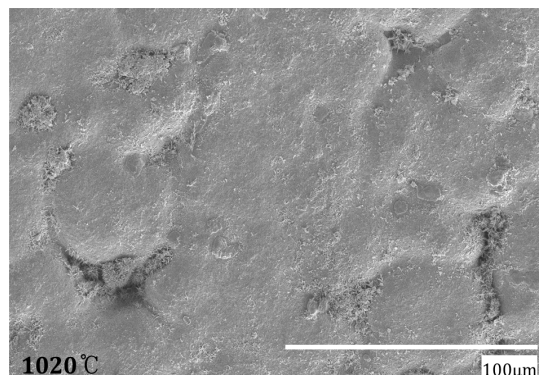

$1020^{\circ} \mathrm{C}$

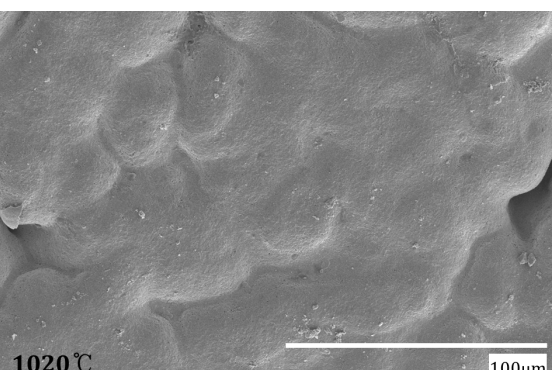

Figure 17. Observation results of surface of pack-chromizing treated layer sintered-steels by SEM for each temperatures. (a) Cr. (b) $7 \mathrm{Cr}-3 \mathrm{Fe}$.

\begin{tabular}{r|c|c|c|c|c}
\hline & $\mathrm{Cr} 2 \mathrm{p}$ & $\mathrm{Fe} 2 \mathrm{p}$ & $\mathrm{C} 1 \mathrm{~s}$ & $\mathrm{O} 1 \mathrm{~s}$ & $\mathrm{Cl} 2 \mathrm{p}$ \\
\hline $930^{\circ} \mathrm{C}$ & 29.56 & 1.4 & 32.03 & 33.96 & 3.05 \\
$970^{\circ} \mathrm{C}$ & 35.83 & 0.38 & 13.83 & 47.48 & 2.47 \\
$1020^{\circ} \mathrm{C}$ & 28.2 & 0.57 & 38.48 & 30.76 & 1.77 \\
\hline
\end{tabular}

\begin{tabular}{c|c|c|c|c|c|c}
\hline & CrK & FeK & CK & Ok & CIK & AlK \\
\hline $930^{\circ} \mathrm{C} 1 \mathrm{hr}$ & 35.8 & 39.6 & & 18.21 & 3.64 & 2.76 \\
$10 \mathrm{hr}$ & 69.05 & 30.12 & & & 0.19 & 0.63 \\
$20 \mathrm{hr}$ & 81.98 & 4.42 & 13.61 & & & \\
$970^{\circ} \mathrm{C} 1 \mathrm{hr}$ & 65.34 & 32.46 & & & 0.31 & 1.88 \\
$10 \mathrm{hr}$ & 93.2 & 6.55 & & & 0.25 & \\
$20 \mathrm{hr}$ & 82.35 & 4.17 & 11.01 & 2.47 & & \\
$1020^{\circ} \mathrm{C} 1 \mathrm{hr}$ & 80.12 & 17.56 & & & 1.32 & 1.01 \\
$10 \mathrm{hr}$ & 90.87 & 9.04 & & & 0.08 & \\
$20 \mathrm{hr}$ & 75.07 & 3.53 & 16.83 & 4.57 & & \\
\hline
\end{tabular}

(a)

(b)

Figure 18. Chemical composition change on the surface in (a) XPS and (b) EDS analysis results in the form of each temperature following on the micro-alloying surface via pack-chromizing treatment.

state. Also, in case of the process at $1020^{\circ} \mathrm{C}$ for 20 hours as that at $930^{\circ} \mathrm{C}$, EDS analysis result shows no $\mathrm{Cl}$. The process for 10 hours shows about $0.08 \%$ of $\mathrm{Cl}$. However, in XPS, a significant amount, about $2 \%$ of $\mathrm{Cl}$ is observed compositions $\mathrm{CrCl}_{x}$ structure.

Through such observations, it is determined by the comparison between EDS analyzing the substances in the deeper layers and XPS analyzing the substances only in the outermost surface that, if the reaction on the surface by the activator as the reaction Equations (5) and (6), when the material metal is with Cr only and exists as the mixture of $7 \mathrm{Cr}-3 \mathrm{Fe}$, it affects the $\mathrm{Cl}$ remaining in the formation of final micro-alloying layer. 
In particular, if crystallized, it is possible for the structure to maintain the strength with no corrosive impact.

Figure 19 shows the X-ray diffraction patterns for the analysis of difference in the phase formation of diffused layer established in the chromium only resource and in the $7 \mathrm{Cr}-3 \mathrm{Fe}$ mixture resource materials under the same pack-chromizing conditions.

The main peaks are observed to be similar, with some degree of difference in $\mathrm{M}_{7} \mathrm{C}_{3}$ and $\mathrm{Cr}_{3} \mathrm{C}_{2}$. However, in the case of chromium only and $7 \mathrm{Cr}-3 \mathrm{Fe}$ mixture resource materials, there may be some difference by the temperature and the time. The results of further study on this phenomenon is not addressed in this paper due to the limited volume of this report but will be reported in the future. Nevertheless, this phenomenon is determined to be related to the change of the result of EDS observed previously.

According to the analysis results of X-ray diffraction (Figure 19), in the chromium case of the short time processes and in the $7 \mathrm{Cr}-3 \mathrm{Fe}$ mixture resource materials at $930^{\circ} \mathrm{C}, 970^{\circ} \mathrm{C}$ and $1020^{\circ} \mathrm{C}$, large amounts of chloride remain on the surface resulting in the formation of a highly strong layer simultaneously with the low friction characteristics. In case of the long time or at the $1020^{\circ} \mathrm{C}$, it is determined that, as $\mathrm{HCl}$ gas is released externally by the hydrogen reduction in the activator due to the sufficient reaction in the chloride deficit layer, chloride gradually percolates inside causing the reduction of amount of the activator.

The X-ray diffraction also shows that there is some difference of shape formation according to temperature but not according to chromium or $7 \mathrm{Cr}-3 \mathrm{Fe}$ mixture resource. However, use of $7 \mathrm{Cr}-3 \mathrm{Fe}$ mixture resource results in thicker layer after same alloying duration.

The uniqueness of this phenomenon is that the amount of chloride in the micro-alloying layer reduces as the temperature increases or the time increases at the same temperature. Compared to the formation of the depleted activator model (activator depleted zone), although rates of the vapor pressure production and the gas diffusion by the activator are uniform on the surface of the alloying metal material, the diffusion distance becomes longer depending on the consumed activator and the alloying material depleted around the sample. Therefore, $\mathrm{HCl}$ gas supplied by the activator reversely reacts on the surface of the material and reversely produces $\mathrm{CrCl}_{x}$ and $\mathrm{FeCl}_{x}$ causing the reduction of the coating layer formation rate. Further, such a reaction results in the reduction of the amount of chloride in the coating layer. Therefore, the results show that the control of an optimized amount of activator is a critical factor in the pack-chromizing process.

\section{Conclusions}

1) Pack-chromizing treatment of sintered steel for the purpose of anti-wear and anti-corrosion properties improvement on the surface is considered to be one of the methods in the surface treatment. The microscopic surface analysis showed $\mathrm{CrCl}_{x}$ (metal chloride) and the comparisons showed some changes in the 

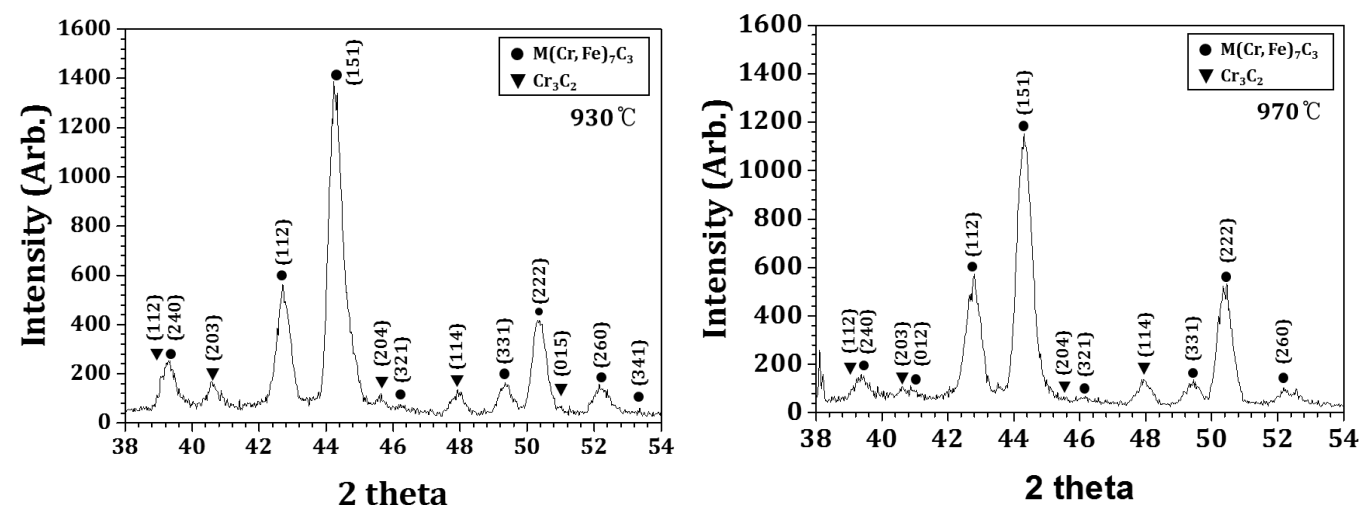

(a)
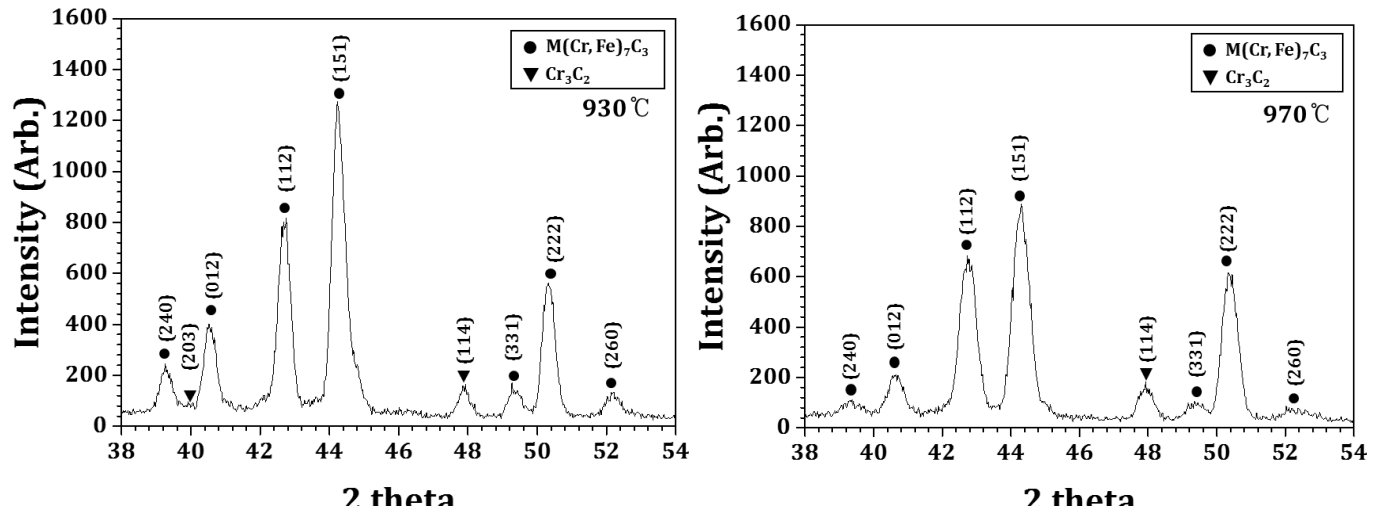

2 theta

2 theta

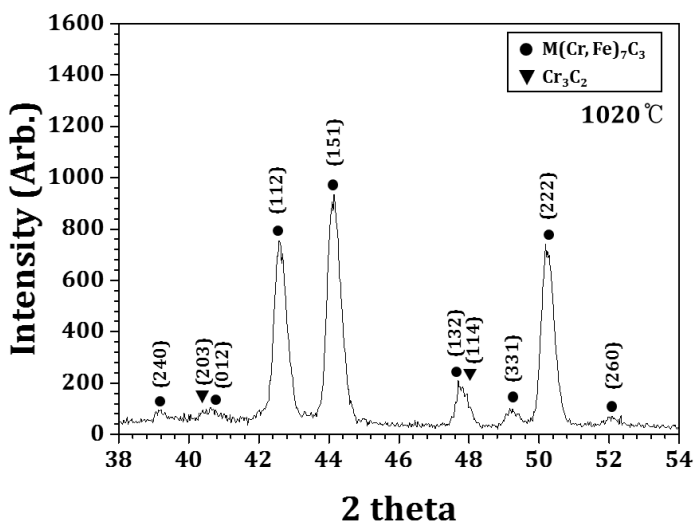

(b)

Figure 19. The results of X-ray diffraction analysis of pack-chromizing treated layer on sintered-steel for chromium only $(\mathrm{Cr})$ and $7 \mathrm{Cr}-3 \mathrm{Fe}$ mixtures resource and process temperatures. (a) $\mathrm{Cr}$. (b) $7 \mathrm{Cr}$-3 Fe mixture. 
friction coefficient even under the same conditions, and it was found that when chloride was observed in the coating layer formed on the surface, there was a very low friction coefficient.

2) The metal carbides $M_{7} C_{3}$ and chromium-iron carbides $\left(\mathrm{Cr}_{3} \mathrm{C}_{2}\right)$ phase were observed to indicate high hardness of the part formed in the conventional pack-chromizing treated on sintered steel. When coating the part after the hydrocarbon gas $\left(\mathrm{C}_{2} \mathrm{H}_{2}\right.$ gas $)$ was added to the inert argon gas, it was found that the phase were formed and more uniform and thicker coated layer was produced compared to that of the conventional pack-chromizing.

3) The chloride content was found to be reduced if the process temperature was high or the time was long although the same amount of activator was used, implying that the activator's depleted zone model was well followed. However, using $7 \mathrm{Cr}-3 \mathrm{Fe}$ mixture as the coating material resulted in the same uniform coating phase but thicker coating layer after same coating duration than using the $\mathrm{Cr}$ only as the coating material.

4) The pack-chromizing process using the sintered steel is considered to be a coating process with a great ripple effect as it can produce the high hardened and corrosion resistant product with low cost surface layer and can yield uniform coating layer and high corrosion resistance that cannot be realized in the wet coating of physical vapor deposition (PVD) process.

\section{References}

[1] Bai, C.-Y., Luo, Y.-J. and Koo, C.-H. (2004) Improvement of High Temperature Oxidation and Corrosion Resistance of Superalloy IN-738LC by Pack Cementation. Surface and Coatings Technology, 183, 74-88. https://doi.org/10.1016/j.surfcoat.2003.10.011

[2] Rohr, P.M.V. (2005) Developpement de revetements pour les aciers d'echangeurs thermiques et amelioration de leur resistance a la corrosion en environnement simulant les fumees de combustion de charbon. Ph. D. Thesis, Institut National Polytechnigue de Toulouse, Toulous, 9-15.

[3] Raoo, R.A. (1992) Technical Report 1. Office of Naval Research, Arlington, 1-64.

[4] Pérez, F.J., Hierro, M.P., Pedraza, F., Gómez, C. and Carpintero, M.C. (1999) Aluminizing and Chromizing Bed Treatment by CVD in a Fluidized Bed Reactor on Austenitic Stainless Steels. Surface and Coatings Technology, 120-121, 151-157. https://doi.org/10.1016/S0257-8972(99)00355-2

[5] Wang, H.-F., Wang, J.-Y. and Wang, H-C. (2011) Segregation of Molten Salt on Chromizing in Thermal Diffusion Process. Journal of Wuhan University of Technology_Materials Science Edition, 26, 1189-1192.

[6] Presnov, V.A., Lyubimov, M.L., Stroganeva, V.V. and Lovshenko, Z.M. (1976) Diffusion Chromizing of Sintered Steels. Poroshkovaya Metallurgiya, 9, 27-31.

[7] Kim, S.G., Park, Y.J., Yeo, K.H. and Lee, J.H. (2012) Corrosion Resistance and Low Friction Property of Sintered Steel Parts via Chromizing Treatment. Korean Journal of Metals and Materials, 50, 809-815. https://doi.org/10.3365/KJMM.2012.50.11.809

[8] Sen, S. (2006) Influence of Chromium Carbide Coating on Tribological Performance of Steel. Materials and Design, 27, 85-91. https://doi.org/10.1016/j.matdes.2004.10.005 